\title{
PENGARUH BRAND CHARACTERISTIC TERHADAP BRAND LOYALTY DIMEDIASI OLEH BRAND TRUST DAN BRAND AFFECT
}

\author{
Mely Rahmawati,Sri Murni Setyawati, Nur Choirul Afif \\ Magister Manajemen, UniversitasJenderalSoedirman Indonesia \\ *Email corresponding author : $\underline{\text { melyfarez84@gmail.com }}$
}

\begin{abstract}
Abstrak
Tujuan penelitian adalah menganalisis pengaruh brand characteristic terhadap brand trust, pengaruh brand characteristic terhadap brand affect, pengaruh brand characteristic terhadap brand loyalty, pengaruh brand trust terhadap brand loyalty, pengaruh brand affect terhadap brand loyalty, mediasi brand trust pada pengaruh brand characteristic terhadap brand loyalty dan mediasi brand affect pada pengaruh brand characteristic terhadap brand loyalty. Penelitian ini adalah penelitian kuantitatif dan diklasifikasikan dalam penelitian asosiatif. Data yang digunakan adalah data primer yang diperoleh dari kuisioner yang dibagikan kepada 125 pengunjung. Owabong sebagai responden. Metode pengambilan sampel yang digunakan adalah purposive sampling. Dalam penelitian ini, data primer diperoleh langsung dari jawaban responden melalui kuesioner. Data hasil penelitian kemudian dianalisis menggunakan Structural Equation Modelling (SEM). Hasil penelitian menunjukkan bahwa: brand characteristic berpengaruh terhadap brand trust, brand characteristic berpengaruh terhadap brand affect, brand characteristic berpengaruh terhadap brand loyalty, brand trust berpengaruh terhadap brand loyalty, brand affect berpengaruh terhadap brand loyalty, brand trust memediasi pengaruh brand characteristic terhadap brand loyalty, brand affect memediasi pengaruh brand characteristic terhadap brand loyalty.
\end{abstract}

\section{Kata Kunci :Brand Characteristic, Brand Trust, Brand Affect, Brand Loyalty}

Abstrac

The aim of the study was to analyze the brand characteristic effect of brand trust, brand characteristic influence on brand affect, brand characteristic influence on brand loyalty, brand trust influence on brand loyalty, brand affect on brand loyalty, brand trust mediation on the influence of brand characteristic on brand loyalty and Brand mediation affects the influence of brand characteristic on brand loyalty. This research is quantitative research and classified in associative research. The data used are primary data obtained from questionnaires distributed to 125 Owabong visitors as respondents. The sampling method used was purposive sampling. In this study, primary data was obtained directly from respondents' answers through questionnaires. The results of the research data were then analyzed using Structural Equation Modeling (SEM). The results showed that: brand characteristic has an effect on brand trust, brand characteristic has an effect on brand affect, brand characteristic has an effect on brand loyalty, brand trust has an effect on brand loyalty, brand affect has an effect on brand loyalty, brand trust mediates the influence of brand characteristic on brand loyalty. brand affect mediates the influence of brand characteristic on brand loyalty.

Key Words: Brand Characteristic, Brand Trust, Brand Affect, Brand Loyalty 


\section{PENDAHULUAN}

Menurut Oliver (2007), dunia bisnis yang terus tumbuh dengan pesatnya menjadi tantangan tersendiri bagi para pelaku usaha agar dapat memenangkan persaingan dan mempertahankan kelangsungan hidup perusahaan. Industri pariwisata menawarkan berbagai objek wisata kepada masyarakat luas dengan karakteristik yang berbeda-beda yang memiliki keunikan dan keunggulan di setiap objek wisata tersebut. Oleh karena itu mereka harus mampu menciptakan objek wisata yang inovatif, kreatif dan kompetitif seperti yang diharapkan pasar sasaran serta mampu menciptakan brand characteristic dan selanjutnya dapat menciptakan brand trust, dan brand affect agar objek wisatanya lebih mudah diterima oleh pasar serta menciptakan brand loyalty. Salah satu objek wisata yang banyak dikunjungi adalah objek wisata Owabong yang terletak di Kecamatan Bojongsari Kabupaten Purbalingga. Objek wisata Owabong menjadi salah satu tujuan wisata yang diminati oleh masyarakat, bukan hanya oleh masyarakat setempat tetapi dari luar daerah atau dari luar kota Purbalingga.

Penelitian ini perlu dilakukan untuk mengetahui factor apa sajakah yang mempengaruhi brand loyalty pengunjung objek wisata Owabong di Kabupaten Purbalingga. Schiffman dan Kanuk (2009) mendefinisikan brand loyalty (loyalitas merek) sebagai preferensi konsumen secara konsisten untuk melakukan pembelian pada merek yang sama pada produk yang spesifik atau kategori pelayanan tertentu. Loyalitas merek sebagai suatu ukuran keterkaitan pelanggan kepada sebuah merek yang mampu memberikan gambaran tentang mungkin tidaknya seorang pelanggan beralih ke merek lain yang ditawarkan oleh kompetitor, terutama jika pada merek tersebut didapati adanya perubahan, baik menyangkut harga ataupun atribut lainnya (Aaker, 2009).

Lau dan Lee (1999) menyatakan bahwa brand characteristic terdiri atas tiga elemenya itu: reputasi merek (brand reputation), kecakapan memprediksi merek (brand predictability), dan kompetensi merek (brand competence). Agar suatu merek dapat memiliki karakter yang tinggi atau baik, maka merek harus mempunyai konsistensi, kualitasnya harus dijaga dari waktu ke waktu, selain tentunya juga harus mempunyai kredibilitas. Kemudian agar tampil menjadi yang terbaik, suatu merek harus terlihat bernilai di pasar sehingga mampu membuat konsumen tertarik membelinya lagi, harus mampu meningkatkan ikatan dan keyakinan terhadap merek tersebut sehingga dapat menciptakan loyalitas pelanggan terhadap merek.

Faktor kepercayaan merek (brand trust) juga dapat mempengaruhi brand loyalty. Menurut Lau dan Lee (1999) kepercayaan terhadap merek adalah kemauan mempercayai merek dengan segala resikonya karena adanya harapan yang dijanjikan oleh merek dalam memberikan hasil yang positif bagi konsumen. Jika suatu merek mampu memenuhi harapan konsumen atau bahkan melebihi harapan konsumen dan memberikan jaminan kualitas pada setiap kesempatan penggunaannya, serta merek tersebut diproduksi oleh perusahaan yang memilikireputasi, makakonsumenakansemakinyakindenganpilihannya dan konsumenakanmemilikikepercayaan pada merek, menyukaimerek, sertamenganggapmerektersebutsebagaibagiandaridirinya.

Faktor lain yang dapat mempengaruhi brand loyalty adalah brand affect. Steen kamp dalam Matz leret al., (2008) berkata konsumen yang sering terlibat dalam suatu produk atau merek tertentu, mereka akan lebih mengerti dan lebih mengenal produk atau merek tersebut. Pendapat ini memberi pemahaman bahwa konsumen akan lebih bisa menilai suatu merek jika konsumen tersebut sering mengkonsumsi / terlibat dalam kegiatan yang diselenggarakan oleh merek tersebut.

\section{TINJAUAN PUSTAKA}

\section{Brand Loyalty}


Menurut Schiffman dan Kanuk (2009) loyalitas merek adalah preferensi konsumen secara konsisten untuk melakukan pembelian pada merek yang sama pada produk yang spesifik atau kategori pelayanan tertentu. Loyalitas merek adalah sebuah komitmen yang kuat dalam berlangganan atau membeli suatu merek secara konsisten dimasa yang akan datang. Tjiptono (2005) juga mendefinisikan brand loyalty sebagai komitmen yang dipegang teguh untuk melakukan pembelian ulang dengan produk yang disukai atau dipercayai secara konsisten di masa mendatang, meskipun pengaruh situasional dan upaya pemasaran berpotensi menyebabkan perilaku beralih ke merek lain.

\section{Kepercayaan Merek (Brand Trust)}

Kepercayaan merek (brand trust) didefinisikan sebagai keinginan pelanggan untuk bersandar pada sebuah merek dengan risiko-risiko yang dihadapi karena ekspektasi terhadap merek itu akan menyebabkan hasil yang positif (Lau dan Lee, 1999). Chaudhuri dan Holbrook (2001) mendefinisikan kepercayaan terhadap merek (brand trust) sebagai kemauan dari ratarata konsumen untuk bergantung kepada kemampuan dari sebuah merek dalam melaksanakan segala kegunaan atau fungsinya. Lebih lanjut Chaudhuri dan Holbrook mengatakan bahwa, secara spesifik, kepercayaan dapat mengurangi ketidakpastian dalam sebuah lingkungan di mana konsumen merasa tidak aman di dalamnya, karena mereka mengetahui bahwa mereka dapat mengandalkan merek yang sudah dipercaya tersebut.

\section{Brand Affect}

Chaudhuri \& Holbrook (2001) mendefinisikan brand affect sebagai kemampuan suatu merek untuk mendatangkan respon emosional positif dari konsumen setelah penggunaan merek tersebut. Berdasar pada definisi tersebut, maka dapat dikatakan juga bahwa brand affect merupakan respon konsumen berupa emosi positif setelah menggunakan suatu merek.Brand Affect adalah sebagai potensi merek untuk menimbulkan respons emosional positif dalam ratarata konsumen sebagai akibat dari penggunaannya (Moorman, Zaltman, \& Deshpande, 1992 dalam Jahangir, et al., 2009).

\section{Karakteristik merek (Brand characteristic)}

Menurut Aaker (1997) karakteristik merek merupakan persepsi konsumen tentang suatu merek yang berkaitan dengan simbol, berbeda dengan merek lain, dan mampumemuaskan konsumen.Keller (2003) mengungkapkan bahwa di dalam benak konsumen terdapat semua hal yang berhubungan dengan merek, seperti pemikiran, perasaan, pengalaman, kesan, persepsi, keyakinan dan sikap-sikap suatu produk atau jasa.

\section{HIPOTESIS PENELITIAN}

\section{Pengaruhbrand characteristicterhadapbrand trust}


Untukmemahamisekaligusmenarikminatkonsumen, makaperusahaanharusmemilikibrand characteristicdan kepercayaanmerek yang kuat di benakkonsumen. Perusahaan yang berhasilmembangun brandcharacteristic

kuatakanmemilikinilaitambahdariperusahaanlain.Hasil penelitianKristianto menunjukkanbahwabrand characteristicberpengaruhterhadapbrand trust. Berdasarkanuraian di atasmakadapatdirumuskanhipotesispenelitiansebagaiberikut:

\section{H1 :Brand characteristicberpengaruh pada brand trustkonsumen.}

\section{Pengaruhbrand characteristicterhadapbrand affect}

Keberadaan merek dianggap sebagai pilar bisnis sehingga dapat menarik minat konsumen untuk memakai produk tersebut. Semakin tinggi brand characteristic yang sesuai dengan kebutugan konsumen pada produk/jasa suatu merek maka akan memiliki brand affect yang semakin tinggi pula. Hasil penelitian yang dilakukan oleh Upamanyu dkk (2015) menunjukkan bahwa brand characteristic yaitu corporate imageberpengaruh signifikan terhadap brand affect konsumen. Berdasarkan uraian di atas maka dapat dirumuskan hipotesis penelitian sebagai berikut:

\section{H2 :Brand characteristicberpengaruh pada brand affect.}

\section{Pengaruhbrand characteristicterhadapbrand loyalty}

Loyalitas terjadi jika ada tanggapan positif dari pengalaman pembelian maupun konsumsi seorang konsumen atas suatu produk.Hasil penelitian Ainun Mardiah (2013) menunjukkan brand characteristic berpengaruh positif signifikan terhadap brand loyalty konsumen. Hasil penelitian Kristianto (2013) menunjukkan brand characteristic berpengaruh positif terhadap loyalitas merek (brand loyalty). Berdasarkan uraian di atas maka dapat dirumuskan hipotesis penelitian sebagai berikut:

\section{H3 : Brand characteristicberpengaruhterhadapbrand loyaltykonsumen.}

\section{Pengaruhbrand trustterhadapbrand loyalty}

Brand Trust memiliki pengaruh yang sangat besar terhadap loyalitas konsumen. Apabila konsumen sudah percaya terhadap merek tersebut tentu konsumen tidak akan berpindah pada merek lain.Hasil penelitian Alhaddad (2014) menunjukkan bahwa kepercayaan merek (brand trust) berpengaruh positif signifikan terhadap loyalitas merek (brand loyalty) konsumen. Hasil penelitian Handayani dan Martini (2015), dan penelitian Afif dkk (2015) menunjukkan bahwa kepercayaan merek (brand trust) berpengaruh positif signifikan terhadap loyalitas merek (brand loyalty). Hasil penelitian Kabadayi dan Alan (2012) menunjukkan kepercayaan merek (brand trust) berpengaruh positif terhadap loyalitas merek (brand loyalty).Berdasarkan uraian di atas maka dapat dirumuskan hipotesis penelitian sebagai berikut:

\section{H4 :Brand trustberpengaruhterhadapbrand loyalty.}

\section{Pengaruhbrand affectterhadapbrand loyalty}


Brand Affect adalah sebagai potensi merek untuk menimbulkan respons emosional positif dalam rata-rata konsumen sebagai akibat dari penggunaannya (Moorman, Zaltman, \& Deshpande, 1992 dalam Jahangir, et al., 2009). Lebih dalam dikemukan oleh Chaudhuri \& Holbrook (2002) bahwa brand affect merupakan pengaruh yang kuat bagi brand loyalty. Merek yang dapat membuat konsumen merasakan bahagia, senang, atau penuh kasih sayang, dapat menimbulkan kesetiaan konsumen pada merek tersebut.Hasil penelitian Lin dan Lee (2012), dan penelitian Afif dkk (2015) menunjukkan bahwa brand affect berpengaruh positif signifikan terhadap loyalitas merek (brand loyalty) konsumen. Hasil penelitian Kabadayi dan Alan (2012) menunjukkan brand affect berpengaruh positif terhadap loyalitas merek (brand loyalty).Berdasarkan uraian di atas maka dapat dirumuskan hipotesis penelitian sebagai berikut:

\section{H5 :Brand affectberpengaruhterhadapbrand loyalty.}

\section{Mediasibrand trust pada pengaruhbrand characteristicterhadapbrand loyalty}

Bilasuatuperusahaanatausuatuprodukdengannamaataumerektertentutelahmemiliki brand image yang baikdarikonsumenmakaakandiikutidenganmeningkatnya brand trust konsumen pada merektersebut. Hal inidisebabkanbrand trust merupakanfaktorpentingdalammenjagahubunganperusahaandengankonsumen, apabilakonsumentelahmemilikikepercayaanterhadapsebuahmerekmakakonsumentersebutakan memilikiintensitaspembelianbarangkembali yang tinggi (Lau \& Lee,1999).Hasil penelitianGozali (2015) menunjukkanbahwabrand trustmemediasipengaruhrisk aversion terhadapbrand loyalty. Hasil penelitian Kurt Matzler, Sonja Grabner dan Kräuter Sonja Bidmon (2008) menunjukkanbahwabrand trustmemediasipengaruhrisk aversion terhadap brand loyalty. Kristianto (2013) menunjukkanbahwapengaruhbrand characteristicterhadapbrand loyaltydimediasi oleh brand trust.Berdasarkanuraian di atasmakadapatdirumuskanhipotesispenelitiansebagaiberikut:

\section{H6 : Brand trust memediasi pengaruh brand characteristicterhadap brand loyalty.} Mediasibrand affect pada pengaruhbrand characteristicterhadapbrand loyalty.

Emosimempengaruhiindividu pada tingkatkesadaran dan bertindaksebagai motivator internal yang menarikseseorangkepadasesuatu yang membuatseseorangmerasabaikatauterkaitpositifdenganpikiran.Hal inimenandakanbahwakaraktermerek (brand characteristic) yang dapatmendatangkanemosipositifdarikonsumenakanmembuatkonsumen loyal terhadapmerektersebut.

Sehinggasemakintinggipengaruhpositifsuatumerekterhadapkonsumenmakasemakintinggitingka tloyalitaskonsumen pada merektersebut. Hal inisesuaidenganpendapat yang dikemukakandalampenelitianMatzler (2008), Singh dan Sirdeshmukh (2012) yang mengatakansemakintinggibrand affect makasemakintinggiloyalitaskonsumen pada 
suatumerek.Hasil penelitianKabadayi dan Alan (2012) menunjukkanbahwabrand affectmemediasipengaruhbrand trust terhadap brand loyalty. Hasil penelitianKurt Matzler, Sonja Grabner dan Kräuter Sonja Bidmon (2008) menunjukkanbahwabrand affectmemediasipengaruhrisk aversion terhadapbrand loyalty.Berdasarkanuraian di atasmakadapatdirumuskanhipotesispenelitiansebagaiberikut:

H7 :Brand affect memediasipengaruh brand characteristicterhadapbrand loyalty.

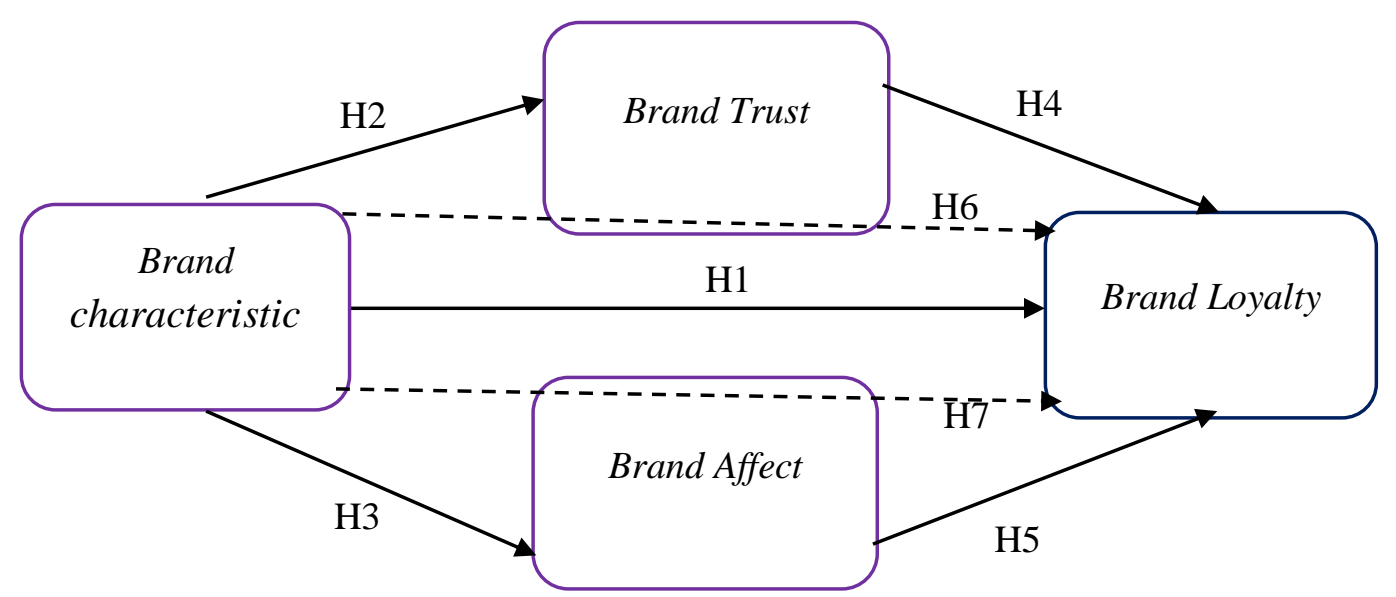

Gambar 1. Model Penelitian

\section{METODE PENELITIAN}

Jenispenelitianiniadalahpenelitian survey denganmenggunakankuisioner.

Populasidalampenelitianiniadalah para pengunjungobjekwisataOwabong

di KecamatanBojongsariKabupatenPurbalingga. Jumlahsampelsebanyak 125 orang. Metodepengambilansampel yang digunakanadalahpurposive sampling. Dalampenelitianini, data primer diperolehlangsungdarijawabanrespondenmelaluikuesioner.

\section{HASIL DAN PEMBAHASAN}

\section{Deskripsi Responden}

Responden pada penelitian ini adalah pengunjung pria maupun wanita yang berusia $>10$ tahun yang pernah berkunjung ke obyek wisata Owabong Kabupaten Purbalingga. Kuesioner disebarkan kepada 125 responden yang berada di Obyek wisata Owabong.

Tabel 1. Distribusi frekuensi deskripsi responden menurut jenis kelamin

\begin{tabular}{lcc}
\hline \multicolumn{1}{c}{ Jenis kelamin } & Frekuensi & Prosentase (\%) \\
\hline Laki-laki & 59 & 47,20 \\
Perempuan & 66 & 52,80 \\
\hline Jumlah & $\mathbf{1 2 5}$ & $\mathbf{1 0 0}$ \\
\hline
\end{tabular}


Tabel 2. Distribusi frekuensi deskripsi responden menurut usia

\begin{tabular}{lcc}
\hline \multicolumn{1}{c}{ Usia (tahun) } & Frekuensi & Prosentase $\mathbf{( \% )}$ \\
\hline$<20$ & 46 & 36,80 \\
$20-30$ & 41 & 32,80 \\
$>30-40$ & 24 & 19,20 \\
$>40$ & 14 & 11,20 \\
\hline Jumlah & $\mathbf{1 2 5}$ & $\mathbf{1 0 0}$ \\
\hline
\end{tabular}

Tabel 3. Distribusi frekuensi deskripsi responden menurut pendidikan

\begin{tabular}{lcc}
\hline \multicolumn{1}{r}{ Pendidikan } & Frekuensi & Prosentase (\%) \\
\hline SD & 6 & 4,80 \\
SMP & 13 & 10,40 \\
SMA & 80 & 64,00 \\
diploma & 7 & 5,60 \\
S1/S2 & 19 & 15,20 \\
\hline Jumlah & $\mathbf{1 2 5}$ & $\mathbf{1 0 0}$ \\
\hline
\end{tabular}

Tabel 4. Distribusi frekuensi deskripsi responden menurut pekerjaan

\begin{tabular}{lcc}
\hline \multicolumn{1}{c}{ Pekerjaan } & Frekuensi & Prosentase (\%) \\
\hline pelajar & 21 & 16,80 \\
PNS & 7 & 5,60 \\
Swasta & 57 & 45,60 \\
Wiraswasta & 18 & 14,40 \\
ibu rumah tangga & 4 & 3,20 \\
tidak disebutkan & 18 & 14,40 \\
\hline Jumlah & $\mathbf{1 2 5}$ & $\mathbf{1 0 0}$ \\
\hline
\end{tabular}

Tabel 5. Hasil uji kausalitas full model : regression test

\begin{tabular}{|lll|cccc|}
\hline & & & Estimate & S.E. & C.R. & P \\
\hline Brand Trust & $<---$ & Brand Characteristic &, 668 &, 062 & 10,786 & $* * *$ \\
Brand Affect & $<---$ & Brand Characteristic &, 913 &, 066 & 13,747 & $* * *$ \\
Brand Loyalty & $<---$ & Brand Trust &, 387 &, 133 & 2,909 &, 004 \\
Brand Loyalty & $<---$ & Brand Affect &, 299 &, 095 & 3,137 &, 002 \\
Brand Loyalty & $<---$ & Brand Characteristic &, 276 &, 139 & 1,988 &, 047 \\
\hline
\end{tabular}

Sumber data diolah

\section{Pengaruh brand characteristic terhadap brand trust}

Nilai CR untuk pengaruh brand characteristic terhadap brand trust adalah lebih besar dari nilai t tabel, yaitu CR>t tabel $(10,786>1,960)$ dan nilai probabilitas 0,000 di bawah 0,05 . Oleh karena itu hipotesa nol ditolak yang berarti pengaruh brand characteristic terhadap brand trust 
adalah signifikan, sehingga hipotesis pertama yang menyatakan brand characteristic berpengaruh terhadap brand trust, diterima.

Hasil analisis data hasil penelitian menggunakan SEM menunjukkan bila nilai CR lebih besar dari t tabel dan nilai probabilitas lebih kecil dari 0,05, yang artinya brand characteristic berpengaruh signifikan terhadap brand trust. Hasil ini menunjukkan bahwa brand dharacteristic dapat menentukan tinggi rendahnya brand trust pengunjung pada brand objek wisata Owabong. Semakin tinggi brand characteristic yang dimiliki Owabong, maka brand trust akan semakin tinggi pula.

Brand characteristic dari Owabong seperti kualitas baik, dapat diandalkan, konsisten kualitasnya, dapat memenuhi dan memuaskan kebutuhan wisata pengunjung, dapat menciptakan kepercayaan pengunjung atas brand owabong. Apabila hal-hal tersebut semakin ditingkatkan oleh Owabong, maka kepercayaan pengunjung bahwa Owabong adalah tempat wisata berkualitas baik dan dapat diandalkan serta memuaskan bisa menjadi semakin tinggi. Hal ini karena Owabong dianggap memiliki ciri khas yang lebih unggul dibanding tempat wisata lain.

Hasil penelitian ini telah membuktikan secara empiris bahwa brand characteristic berpengaruh terhadap brand trust. Hasil ini sesuai dengan pendapat Setiadi (2003) yaitu bahwa konsumen membentuk presepsi terhadap merek melalui informasi yang mereka dapatkan dengan presepsi terhadap merek yang baik, maka kepercayaan merek juga akan meningkat. Kepercayaan konsumen dapat juga dibangun melalui karakteristik merek dari suatu produk yang dinilai baik oleh masyarakat sehingga dapat menimbulkan rasa percaya dan pembelian konsumen. Hasil penelitian ini sesuai dengan hasilpenelitian yang dilakukan oleh Kristianto (2013) menunjukkan bahwa brand characteristic berpengaruh terhadap brand trust.

\section{Pengaruh brand characteristic terhadap brand affect}

Nilai CR untuk pengaruh brand characteristic terhadap brand affect adalah lebih besar dari nilai $t$ tabel, yaitu CR>t tabel $(13,747>1,960)$ dan nilai probabilitas 0,000 di bawah 0,05 . Oleh karena itu hipotesa nol ditolak yang berarti pengaruh brand characteristic terhadap brand affect adalah signifikan, sehingga hipotesis kedua yang menyatakan brand characteristic berpengaruh terhadap brand affect, diterima.

Hasil analisis data hasil penelitian menggunakan SEM menunjukkan bila nilai CR lebih besar dari t tabel dan nilai probabilitas lebih kecil dari 0,05, yang artinya brand characteristic berpengaruh signifikan terhadap brand affect. Hasil ini menunjukkan bahwa brand dharacteristic dapat menentukan tinggi rendahnya brand affect pengunjung pada brand objek wisata Owabong. Semakin tinggi brand characteristic yang dimiliki Owabong, maka brand affect pada pengunjung akan semakin tinggi pula.

Hasil penelitian ini juga dapat menunjukkan bahwa objek wisata Owabong memiliki merek atau brand yang mendapat respon positif dan mendapat persepsi baik dan meyakinkan oleh 
pengunjung, dan mampu menciptakan perasaan senang, bahagia, aman, dan nyaman saat menggunakan atau menikmati berwisata di Owabong. Hasil penelitian ini menunjukkan kesesuaian dengan pendapat Chaudhuri \& Holbrook (2001) mendefinisikan brand affect sebagai kemampuan suatu merek untuk mendatangkan respon emosional positif dari konsumen setelah penggunaan merek tersebut. Hasil penelitian ini telah mebuktikan secara empiris bila brand characteristic berpengaruh terhadap brand affect. Semakin tinggi brand characteristic yang sesuai dengan kebutuhan konsumen pada produk/jasa suatu merek maka akan memiliki brand affect yang semakin tinggi pula. Hasil penelitian ini sesuai dengan hasil penelitian yang dilakukan oleh Upamanyu dkk (2015) yang menunjukkan bahwa brand characteristic yaitu corporate imageberpengaruh signifikan terhadap brand affect konsumen.

\section{Pengaruh brand characteristic terhadap brand loyalty}

Nilai CR untuk pengaruh brand characteristic terhadap brand loyalty adalah lebih besar dari nilai t tabel, yaitu CR>t tabel $(1,988>1,960)$ dan nilai probabilitas 0,047 di bawah 0,05. Oleh karena itu hipotesa nol ditolak yang berarti pengaruh brand characteristic terhadap brand loyalty adalah signifikan, sehingga hipotesis ketiga yang menyatakan brand characteristic berpengaruh terhadap brand loyalty, diterima.

Hasil analisis data hasil penelitian menggunakan SEM menunjukkan bila nilai CR lebih besar dari t tabel dan nilai probabilitas lebih kecil dari 0,05, yang artinya brand characteristic berpengaruh signifikan terhadap brand loyalty. Hasil ini menunjukkan bahwa brand characteristic dapat menentukan tinggi rendahnya brand loyalty pengunjung pada objek wisata Owabong. Semakin tinggi brand characteristic yang dimiliki Owabong, maka brand loyalty pengunjung akan semakin tinggi pula.

Brand characteristic dari Owabong yang selama ini dikenal dengan tempat wisata dengan kualitas baik, dapat diandalkan, konsiiten kualitasnya, dapat memenuhi dan memuaskan kebutuhan wisata pengunjung, telah menciptakan loyalitas pengunjung atas brand Owabong. Apabila hal-hal tersebut semakin ditingkatkan oleh Owabong, maka loyalitas pengunjung bisa menjadi semakin tinggi. Hal ini karena Owabong oleh pengunjung dianggap lebih unggul dibanding tempat wisata lain, sehingga pengunjung ingin berkunjung kembali. Loyalitas terjadi jika ada tanggapan positif dari pengalaman pembelian maupun konsumsi seorang konsumen atas suatu produk.Meski banyak objek wisata yang ada, namun pengunjung yang setia untuk mengunjungi Owabong, kondisi ini sebagaimana pendapat yang dikemukan Oliver dalam

Hasil penelitian ini telah membuktikan secara empiris bahwa brand characteristic berpengaruh terhadap brand loyalty. Semakin tinggi brand characteristic yang dimiliki Owabong maka brand loyalty akan semakin tinggi pula. Hasil penelitian ini disukung oleh hasil penelitian Ainun Mardiah (2013) yang menunjukkan brand characteristic berpengaruh positif signifikan terhadap brand loyalty konsumen. Hasil penelitian ini juga didukung oleh hasil penelitian 
Kristianto (2013) menunjukkan brand characteristic berpengaruh positif terhadap loyalitas merek (brand loyalty).

\section{Pengaruh brand tustterhadap brand loyalty}

Nilai CR untuk pengaruh brand trust terhadap brand loyalty adalah lebih besar dari nilai $t$ tabel, yaitu CR>t tabel $(2,909>1,960)$ dan nilai probabilitas 0,004 di bawah 0,05. Oleh karena itu hipotesa nol ditolak yang berarti pengaruh brand trust terhadap brand loyalty adalah signifikan, sehingga hipotesis keempat yang menyatakan brand trust berpengaruh terhadap brand loyalty,

\section{diterima.}

Hasil analisis data hasil penelitian menggunakan SEM menunjukkan bila nilai CR lebih besar dari $\mathrm{t}$ tabel dan nilai probabilitas lebih kecil dari 0,05, yang artinya brand trust berpengaruh signifikan terhadap brand loyalty. Hasil ini menunjukkan bahwa brand trust dapat menentukan tinggi rendahnya brand loyalty pengunjung pada objek wisata Owabong. Semakin tinggi brand trust dari Owabong, maka brand loyalty pengunjung akan semakin tinggi pula.

Pengunjung memiliki kepercayaan bahwa Owabong beserta ragam wahana wisatanya adalah tempat wisata yang baik yang dapat diharapkan dapat membuat mereka senang dan memuaskan, sehingga tidak sungkan untuk kembali berkungjung ke Owabong. Hal ini sebagaimana pendapat Lau dan Lee (1999) bahwa kepercayaan terhadap merek adalah kemauan mempercayai merek dengan segala resikonya karena adanya harapan yang dijanjikan oleh merek dalam memberikan hasil yang positif bagi konsumen. Hasil penelitian ini didukung oleh hasil penelitian Alhaddad (2014) menunjukkan bahwa kepercayaan merek (brand trust) berpengaruh positif signifikan terhadap loyalitas merek (brand loyalty) konsumen. Hasil penelitian ini juga didukung oleh penelitian Handayani dan Martini (2015), serta penelitian Afif dkk (2015) yang hasilnya menunjukkan bahwa kepercayaan merek (brand trust) berpengaruh positif signifikan terhadap loyalitas merek (brand loyalty). Demikian pula didukung oleh hasil penelitian Kabadayi dan Alan (2012) menunjukkan kepercayaan merek (brand trust) berpengaruh positif terhadap loyalitas merek (brand loyalty).

\section{Pengaruh brand affect terhadap brand loyalty}

Nilai CR untuk pengaruh brand affect terhadap brand loyalty adalah lebih besar dari nilai t tabel, yaitu CR>t tabel $(3,137>1,960)$ dan nilai probabilitas 0,002 di bawah 0,05 . Oleh karena itu hipotesa nol ditolak yang berarti pengaruh brand affect terhadap brand loyalty adalah signifikan, sehingga hipotesis kelima yang menyatakan brand affect berpengaruh terhadap brand loyalty, diterima.

Hasil analisis data hasil penelitian menggunakan SEM menunjukkan bila nilai CR lebih besar dari t tabel dan nilai probabilitas lebih kecil dari 0,05, yang artinya brand affect berpengaruh signifikan terhadap brand loyalty. Hasil ini menunjukkan bahwa brand affect dapat menentukan 
tinggi rendahnya brand loyalty pengunjung pada objek wisata Owabong. Semakin tinggi brand affect dari Owabong, maka brand loyalty pengunjung akan semakin tinggi pula.

Hasil penelitian ini menunjukkan emosi positif pengunjung pada Owabong, sehingga dari emosi positif ini memunculkan keinginan untuk kembali lagi ke Owabong di masa mendatang. Hal ini sebagaiman pendapat Moorman, Zaltman, \& Deshpande, 1992 dalam Jahangir, et al., (2009) bahwa Brand Affect adalah sebagai potensi merek untuk menimbulkan respons emosional positif dalam rata-rata konsumen sebagai akibat dari penggunaannya. Hasil penelitian ini telah membuktikan secara empiris bahwa brand affect berpengaruh terhadap brand loyalty. Hasil ini didukung oleh pendapat dari Chaudhuri \& Holbrook (2002) bahwa brand affect merupakan pengaruh yang kuat bagi brand loyalty. Merek yang dapat membuat konsumen merasakan bahagia, senang, atau penuh kasih sayang, dapat menimbulkan kesetiaan konsumen pada merek tersebut. Hasil penelitian ini didukung oleh hasil penelitian Lin dan Lee (2012), dan penelitian Afif dkk (2015) yang menunjukkan bahwa brand affect berpengaruh positif signifikan terhadap loyalitas merek (brand loyalty) konsumen. Hasil penelitian ini juga didukung oleh penelitian Kabadayi dan Alan (2012) yang hasilnya menunjukkan bahwa brand affect berpengaruh positif terhadap loyalitas merek (brand loyalty).

\section{Mediasi brand trust pada pengaruh brand characteristic terhadap brand loyalty}

Hasil uji sobel pada brand trust seperti yang tertera pada Tabel 4.18 menunjukkan perolehan nilai t hitung sebesar 2,798 lebih besar dari tabel 1,960 (2,798>1,960). Nilai ini menunjukkan bahwa brand trust memediasi pengaruh brand characteristic terhadap brand loyalty. Oleh karena itu hipotesa nol ditolak yang berarti brand trust memediasi pengaruh brand characteristic terhadap brand loyalty, sehingga hipotesis keenam yang menyatakan brand trust memediasi pengaruh brand characteristic terhadap brand loyalty, diterima.

Hasil analisis data hasil penelitian menggunakan SEM menunjukkan bila nilai $t$ lebih besar dari t tabel, yang artinya brand trust memdiasi pengaruh brand characteristik terhadap brand loyalty. Hasil ini menunjukkan bahwa brand affect dapat menguatkan pengaruh brand characteristic terhadap brand loyalty pengunjung pada objek wisata Owabong.

Brand characteristik yang dimiliki oleh Owabong mampu menciptakan brand trust pengunjung, sehingga pengunjung tidak segan berkunjung kembali ke Owabong. Hal ini sebagaimana pendapat Chaudhuri \& Holbrook (2001) bahwa ketika konsumen percaya pada suatu merek, maka frekuensi pembelian akan meningkat.Hasil penelitian ini telah membuktikan secara empiris bahwa brand trust memediasi pengaruh brand characteristic terhadap brand loyalty. Semakin tnggi kepercayaan pengunjung terhadap Owabong maka semakin tinggi loyalitas pengunjung. Hasil ini sesuai dengan pendapat Gozali (2015) dalam penelitiannya juga mengemukakan bahwa semakin tinggi konsumen percaya akan kinerja sebuah merek, maka akan meningkatkan loyalitas konsumen terhadap merek tersebut. Sehingga dapat dikatakan 
bahwa semakin tinggi brand characteristic maka akan semakin tinggi tingkat kepercayaan konsumen terhadap suatu merek (brand trust), yang pada akhirnya semakin meningkatkan tingkat loyalitas konsumen pada merek tersebut (brand loyalty).

Hasil penelitian ini didukung oleh hasil penelitian Gozali (2015) menunjukkan bahwa brand trust memediasi pengaruh risk aversion terhadap brand loyalty. Hasil penelitian ini juga didukung oleh hasil penelitian Kurt Matzler, Sonja Grabner dan Kräuter Sonja Bidmon (2008) yang menunjukkan bahwa brand trust memediasi pengaruh risk aversion terhadap brand loyalty. Demikian pula didukung oleh penelitian Kristianto (2013) yang hasilnya menunjukkan bahwa pengaruh brand characteristic terhadap brand loyalty dimediasi oleh brand trust.

\section{Mediasi brand affect pada pengaruh brand characteristic terhadap brand loyalty}

Hasil uji sobel pada brand affect seperti yang tertera pada Tabel 4.18 menunjukkan perolehan nilai t hitung sebesar 3,061 lebih besar dari tabel 1,960 (3,061>1,960). Nilai ini menunjukkan bahwa brand affect memediasi pengaruh brand characteristic terhadap brand loyalty. Oleh karena itu hipotesa nol ditolak yang berarti brand affect memediasi pengaruh brand characteristic terhadap brand loyalty, sehingga hipotesis keenam yang menyatakan brand affect memediasi pengaruh brand characteristic terhadap brand loyalty, diterima.

Hasil analisis data hasil penelitian menggunakan SEM menunjukkan bila nilai t lebih besar dari t tabel, yang artinya brand affect memediasi pengaruh brand characteristic terhadap brand loyalty. Hasil ini menunjukkan bahwa bila brand affect dapat menguatkan pengaruh brand characteristic terhadap brand loyalty pengunjung pada objek wisata Owabong. Semakin tinggi brand characteristic yang dimiliki Owabong maka brand affect dari pengunjung pada Owabong juga tinggi, dan pada akhirnya brand loyalty pengunjung akan semakin tinggi pula. Hal ini karena merek dapat merepresentasikan persepsi dan perasaan konsumen atas sebuah produk dan kinerjanya kepada konsumen. Nilai nyata dari sebuah merek yang kuat adalah kekuatannya untuk menangkap preferensi dan loyalitas konsumen. Merek mempunyai jumlah kekuatan dan nilai yang sangat beragam di pasar.

Brand characteristic akan membentuk brand affect pada diri konsumen. Emosi mempengaruhi individu pada tingkat kesadaran dan bertindak sebagai motivator internal yang menarik seseorang kepada sesuatu yang membuat seseorang merasa baik atau terkait positif dengan pikiran. Hal ini menandakan bahwa karakter merek (brand characteristic) yang dapat mendatangkan emosi positif dari konsumen akan membuat konsumen loyal terhadap merek tersebut. Hasil penelitian ini membuktikan secara empiris bahwa brand affect memediasi pengaruh brang characteristic terhadap brand loyalty. Sehingga semakin tinggi pengaruh positif suatu merek terhadap konsumen maka semakin tinggi tingkat loyalitas konsumen pada merek tersebut. Hal ini sesuai dengan pendapat yang dikemukakan dalam penelitian Matzler (2008), 
Singh dan Sirdeshmukh (2012) yang mengatakan semakin tinggi brand affect maka semakin tinggi loyalitas konsumen pada suatu merek.

Hasil penelitian ini didukung oleh hasil penelitian Kabadayi dan Alan (2012) yang menunjukkan bahwa brand affect memediasi pengaruh brand trust terhadap brand loyalty. Hasil penelitian ini juga didukung oleh penelitian Kurt Matzler, Sonja Grabner dan Kräuter Sonja Bidmon (2008) yang menunjukkan bahwa brand affect memediasi pengaruh risk aversion terhadap brand loyalty.

\section{KESIMPULAN}

Berdasarkan analisa Hasil penelitian menunjukan bahwa brand characteristic berpengaruh positif terhadap brand trust, brand characteristic berpengaruh positif terhadap brand affect , brand characteristic berpengaruh positif terhadap band loyalty, brand trust berpengaruh positif terhadap brand loyalty, brand affect berpengaruh terhadap brand loyalty, brand trust memediasi pengaruh brand characteristic terhadap brand loyalty, dan brand affect memediasi pengaruh brand characteristic terhadap brand loyalty pengunjung di obyek wisata Owabong Kabupaten Purbalingga.

\section{IMPLIKASI}

\section{Implikasi Teoritis}

Penelitianinimemberikankontribusimengenaihasilpenelitiantentangpengaruhbrand characteristic terhadap brand loyalty dimediasi oleh brand trust dan brand affect.Peneliti menyadari bahwa dalam penyusunan tesis ini masih banyak kekurangan yang disebabkan oleh keterbatasan peneliti. Keterbatasan tersebut antara lain, penelitian hanya menggunakan satu variabel bebas dan dua variabel mediasi dalam melakukan penelitian brand characteristic terhadap brand loyalty dengan brand trust dan brand affect sebagai pemediasi. Saran bagi penelitian selanjutnya diharapkan dapat menambahkan variabel bebas lainnya seperti brand image, citra perusahaan dan kualitas pelayanan atau mengganti variabel mediasi dengan variabel lain misalnya variabel sikap, kepuasan dan brand equity. Sampel dalam penelitian ini bersifat heterogen, sehingga berdampak adanya perbedaan dalam memahami pernyataan dalam kuesioner sehingga sangat mungkin jawaban responden menjadi bias, sehingga saran bagi peneltian selanjutnya menggunakan sampel penelitian yang bersifat homogen, agar terjadinya bias data dapat diminimalisir atau dihilangkan.

Metode pengumpulan data dalam penelitian ini hanya menggunakan kuesioner, sehingga data yang terkumpul sangat mungkin bersifat subyektif untuk penelitian selanjutnya diharapkan dapat menambahkan metode lainnya seperti wawancara, observasi atau metode lain untuk mendapatkan informasi yang menyeluruh dan lebih mendalam. Pada penelitian ini, penelitihanyamelakukanpenelitian 
objekwisataOwabongsajatidakmembandingkandenganobjekwisata lain seperti Dreamland Park atauPurbayasa, sehingga untuk penelitian selanjutnya diharapkan menambah atau membandingkan obyek penelitian dengan obyek wisata lain.

\section{Implikasi Praktis}

Secara keseluruhan hasil penelitian ini telah memberikan bukti bahwa brand characteristic memberi pengaruh kepada brand trust dan brand affect dan brand trust memediasi pengaruh brand characteristic terhadap brand loyalty, dan brand affectmemediasi pengaruh brand characteristic terhadap brand loyalty , serta brand characteristic berpengaruh terhadap brand loyalty. Kedepannya, Owabongharus mempunyai beberapa tindakan strategis untuk meningkatkan brand characteristic Owabong, karena terbukti brand characteristic berpengaruh terhadap brand loyalty. Misalnya menguatkan karakter yang sudah ada dengan menambah image/simbol owabong sehingga lebih menguatkan brand characteristic Owabong. Pihak Owabong sebaiknya meningkatkan brand trust pengunjung, karena selain terbukti berpengaruh terhadap brand loyalty juga menguatkan pengaruh brand characteristic terhadap brand loyalty. Hal ini dapat dilakukan dengan konsistensi Owabong pada kualitasnya baik dari segi kenyaamanan, keamanan, dan kebersihan semua tempat wahana wisata juga dalam memberikan pelayanan kepada pengunjung.Pihak Owabong sebaiknya meningkatkan brand affect pengunjung, karena selain terbukti berpengaruh terhadap brand loyalty juga menguatkan pengaruh brand characteristic terhadap brand loyalty. Hal ini dapat dilakukan dengan membuat suasana Owabong sebagai tempat rekreasi yang menyenangkan, aman dan berkesan bagi pengunjung dari semua golongan umur.

\section{DAFTAR PUSTAKA}

Aaker, David A. 1997, ManajemenEkuitasMerek, Jakarta: Spektrum Mitra Utama. Adkon, Riduwan. 2006. Metode dan tekhnikMenyusunTesis. Bandung :Alfabeta.

Afif, Nur Choirul, Dian UtamiSutiksno, NugrohoHerdiyanto, AldinaShiratina, 2015. Building Drand Loyalty Through Increasing Brand Trust And Brand Affect. International Journal of Scientific Technology Research. Vol. 4, Issue 1. Pp. 336-340.

Afzaal Ali, Guo Xiaoling, Mehkar Sherwani, Adnan Ali, 2018. "Antecedents of consumers' Halal brand purchase intention: an integrated approach", Management Decision,

AinunMardiah, 2013, PengaruhBrand Characteristic dan Company Characteristic TerhadapBrand Loyalty pada Pelanggan Tas Shopie Martin di Kota Pekanbaru, JurnalImuKomputer dan Bisnis, Vol. 4, No. 1, Hal. 665-686. 
Alhaddad, Abdullah. 2015. Perceived Quality, Brand Image and Brand Trust as Determinants of Brand Loyalty. Journal of Research in Business and Management. Volume 3 Issue 4. pp: 01-08. www.questjournals.org.

Ambadar, Jackie. 2007. MengelolaMerek. Jakarta: Yayasan Bina KarsaMandiri.

Arikunto S, 2010. ProsedurPenelitianSuatuPendekatanPraktik. Jakarta: PT RinekaCipta.

Chaudhuri, A. and Holbrook, M.B. 2001, "The chain of effects from brand trust and brand affect to brand performance: the role of brand loyalty", Journal of Marketing, Vol. 65 No. 2, pp. 8193.

Creed. WED. dan Miles, RE. 1996. "Trust in Organization: Aconceptual Framework Linkin Organizational Forms, Managerial Philosophies, and the Opportunity Cost of Controll." In RM. Kramer and TR. Tyler (eds). Trust in Organization: Frontiers of Theory and Research, Sage Publication Inc.

Delgado-Ballester, E. and Munuera-Alemán, J. L. (2001). Brand Trust in the Context of Consumer Loyalty. European Journal of Marketing, Vol. 35, 1238-1258.

Dick, Alan S.dan KunalBasu, 1994. Customer Loyalty: Toward an Integrated Conceptual Framework. Journal of the Academy of Marketing Science. Volume 22, No. 2, pp. 99-113.

Doney, PM. dan Cannon, JP. 1997. "An Examination of The Nature of Trust in Buyer-Seller Relationships," Journal Of Marketing. Vol. 4, No.2, pp. 33-51.

Ferdinand, Augusty. 2012. Structural Equation Modelling DalamPenelitianManajemenAplikasi Model - Model RumitDalamPenelitianuntukTesis Magister dan DisertasiDoktor. Semarang : BP UNDIP.

Gozali, Andi. 2015. Pengaruh Risk Aversion, Brand Trust dan Brand Affect Terhadap Brand Loyalty Gadget Merek Apple di Surabaya. JurnalImiahMahasiswaUniversitas Surabaya. Vol. 4, No.1, hal. 1-16.

Ghozali, Imam. 2011. AplikasiAnalisis Multivariate dengan Program SPSS. Semarang: Badan PenerbitUniversitasDiponegoro.

Gounaris,S. dan Stathakopoulos,V. (2004). Antecedents and consequences of brand loyalty: an empirical study. Journal of Brand Management, 11(4), 283-306.

Gurviez, Patricia, dan M. Korchia. 2003. Test of a consumer-brand relationship model including trust and three consequences. Makalah Seminardalam 30 tahun International Research Seminar in Marketing.

Hair, J. F. JR., Anderson, R.E, Tatham, R.L. and Black, W.C. 2010. Multivariate Data Analysis.Six Edition. New Jersey : Pearson Educational, Inc.

Handayani, SB dan Martini, Ida. 2015. Pengaruh Brand Image Terhadap Brand Loyalty Brand Trust SebagaiVariabelMediasi (StudiEmpiris pada Pemakai Motor Matic Merek Yamaha di 
Kota Semarang). Seminar and call for papaer 2015 Strategic Agility:Thrivein Turbulent Environment (Research and Practices). Hotel Grasia, Semarang.

Jahangir, Nadim; Parves, Noorjahan; Bhattacharjee, Dhrubanil; Ahamed, Khondaker Khaled.,2009. The Relationship Between Brand Affect, Brand Quality, and Customers' BrandExtension Attitude: Exploring The Mediating Role of Customer Loyalty. TheCambodian Management Journal. Vol. 1, No. 1, 20-34.

Kabadayi, Ebru Tümer dan AlevKocak Alan. 2012. Brand Trust and Brand Affect Their Strategic Importance on Brand Laoyalty.Journal of Global Strategic Management. Vol. 6, N0. 1. Pp 80-88.

Keller, K.L. 2008. Strategic Brand Management. Prentice-Hall.

Kotler, P. \& Keller, K. 2008. ManajemenPemasaran(ed.12, Vol. 1). Terjemahan oleh Benyamin Molan. Jakarta: PT Indeks.

Kotler, Philip. 2005. Dasar-dasarPemasaran. Edisi Ke-9 Jilid, Jakarta: Indek.

Kotler, Philip dan Kevin Lane Keller. 2009. ManajemenPemasaran. Edisi ke-13.Terjemahanoleh Benyamin Molan. PT Indeks.

Kristianto, Herbowo. 2013. PeranKepercayaanMerekSebagaiVariabelMediasi Antara KarakteristikMerekDenganLoyalitasMerekProdukCinderamata DAGADU DJOKDJA. JurnalPenelitian.UniversitasAtma Jaya Yogyakarta. Hal. 1-14.

Lau, G. and Lee, S. 1999. Consumer Trust in a Brand and The Link to Brand Loyalty.Journal of Market - Focused Management. International Canadian Center of Science and education. ISSN 2952-3951 Vol.4 No.4, Pp.341-370.

Lin, Miao-Que dan Bruce C. Y. Lee. 2012. The Influence of WebssiteEnvirontment on Brand Loyalty: Brand Trust and Brand Affect as Mediators. International Journal of Electronic Business Management, Vol. 10, No. 4, pp. 308-321.

Matzler, K., Krauter, S.G. and Bidmon, S. 2008, "Risk aversion and brand loyalty: the mediatingrole of brand trust and brand affect", Journal of Product and Brand Management, Vol. 17 No. 3,pp. 154-162.

Morgan, Robert M. \& Hunt, Shelby D. (1994). The Commitment-Trust Theory of Relationship Marketing. The Journal of Marketing, Vol. 58, No. 3 (Jul., 1994), pp.20-38.

Oliver, R.L. 1997, Satisfaction: A Behavioral Perspective on the Consumer, McGraw-Hill, New York, NY.

Oliver. 2007. Measurement and Evaluation of Satisfaction Processes in Retail Settings. Journal of Retailing. Vol. 57, No. 3. Pp.25-48.

Rafiq, M. 2009. PengaruhKepercayaanKonsumen pada MerelTerhadapLoyalitasMerek. JurnalOptina. Vol. 3, No. 1. Hal. 31-40.

Rangkuti, Fredy, 2002. The Power Of Brands, Jakarta: GramediaPustaka Utama. 
Rangkuti, Freddy. 2009. StrategiPromosi yang Kreatif dan AnalisisKasus Integrated Marketing Communication. Jakarta: PT. GramediaPustaka Utama.

Rizan, Mohammad, BasrahSaidani\&Yusiyana Sari. (2012). Pengaruh Brand Image dan Brand trust Terhadap Brand loyalty TehBotolSosroSurveiKonsumenTehBotolSosro Di Food Court ItcCempaka Mas, Jakarta Timur. JurnalRisetManajemenSains Indonesia (Jrmsi). Vol. 3, No. 1, 2012.

Schiffman, Leon and Leslie Lazar Kanuk. 2008. PerilakuKonsumen. Prentice Hall, New Jersey.

Setiadi, Nugroho, SE., MM., 2003, "PerilakuKonsumenKonsep dan ImplikasiuntukStrategi dan PenelitianPemasaran”. Jakarta: Kencana.

Singh, J. dan Sirdeshmukh, D., 2012, "Agency and trust mechanisms in consumer satisfaction and loyalty judgments," Journal of Academy ofMarketing Science, Vol. 28, No.1, pp. 150-167.

Sitkin, SB dan Rooth, NL. 1993. "Explanning the Effectiveness of Legalistic Remidie for Trust /Distrust". Focus Issue: The Legalistic Organization, Organizational Science. Vol. 4. No.3. pp. 367-392.

Sugiyono. 2012. MetodePenelitian Pendidikan (PendekatanKuantitatif, Kualitatif, dan R\&D). Bandung: Alfabeta.

Suliyanto. 2011. EkonometrikaTerapan :Teori\&Aplikasidengan SPSS. Yogyakarta: CV. Andi Offset.

Surachman S.A. 2008. Dasar-Dasar ManajemenMerek. EdisiPertama.MalangBayumedia Publishing.

Tjahyadi, RullyArlan. 2006. Brand Trust dalamKonteksLoyalitasMerek: PeranKarakteristikMerek, Karakteristik Perusahaan, dan KarakteristikHubunganPelanggan-Merek. JurnalManajemen, Vol. 6, No.1, Hal 1-12.

Tjiptono, Fandy. 2005. StrategiPemasaran. Edisi III Andi, Yogyakarta.

Tjiptono, Fandy. 2005. Brand Management \& Strategy. Andi. Yogyakarta.

. Upamannyu, Nischay K, S.S Bhakar dan Mansi Gupta. 2015. Effect of Corporate Image on Brand Trust and Brand Affect. International Journal of Applied Science-Research and Review (IJAS). Vol.2, No.1. Pp. 20-33. www.ijas.org.uk. 